\title{
SIETE VIDAS DE LA TEORÍA PEDAGÓGICA
}

\author{
SETE VIDAS DA TEORIA PEDAGÓGICA
}

SEVEN LIVES OF PEDAGOGICAL THEORY

BRAILOVSKY, Daniel ${ }^{1}$

\section{RESUMEN}

Se propone una reflexión alrededor de la idea de "teoría" en educación, esto es, sobre los diferentes sentidos que se atribuye a la teoría en el pensamiento pedagógico. Se exploran entonces siete hipótesis, como siete modos de concebir la teoría, a saber: 1. La teoría como reglamento: una guía para la acción; 2. La teoría como escritura sagrada: un canon elevado; 3. La teoría como herramienta: una batería de recursos; 4. La teoría como fundamentación o código de ética: un respaldo; 5 . La teoría como vocabulario: un glosario para mirar; 6. La teoría como pensamiento: revisión constante del sentido y 7 . La teoría como conversación.

Palabras clave: Pedagogía. Teoría pedagógica. Metodología.

\section{RESUMO}

Propõe-se uma reflexão acerca da ideia de "teoría" em educação. Isto é, sobre os diferentes sentidos que se atribui à teoria no pensamento pedagógico. Exploram-se sete hipóteses, como sete modos de conceber a teoria, a saber: 1. A teoria como regulamento: um guia para a ação; 2 . A teoria como escritura sagrada: um cânone elevado; 3. A teoria como ferramenta: uma bateria de recursos; 4. A teoria como fundamentação ou código de ética: um respaldo; 5 . A teoria como vocabulário: um glossário para olhar; 6. A teoria como pensamento: revisão constante d sentido, e 7. A teoria como conversação.

Palavras-chave: Pedagogia. Teoria pedagógica. Metodologia.

\section{ABSTRACT}

A reflection is proposed around the idea of "theory" in education. About the different meanings attributed to the theory in pedagogical thinking. Seven hypotheses are then explored, such as seven ways of conceiving the theory, namely: 1 . The theory as a regulation: a guide for action; 2 . The theory as sacred scripture: an elevated canon; 3 . The theory as a tool: a battery of resources; 4 . The theory as a foundation or code of ethics: an endorsement; 5 . Theory as vocabulary: a glossary to look at; 6 . Theory as thought: constant review of meaning, and 7 . Theory as conversation

Palabras clave: Pedagogy. Pedagogical theory. Methodology.

\footnotetext{
${ }^{1}$ Faculdade Latino-Americana de Ciências Sociais - FLACSO - Buenos Aires - Argentina.
} 


\section{CONVERSAR, PENSAR, ESCRIBIR}

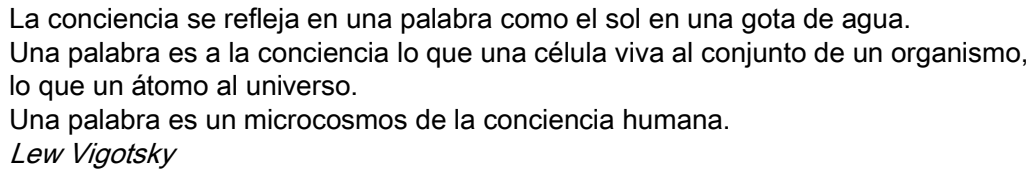

¿A qué llamamos pedagogía? ¿Qué es, o qué son las pedagogías? ¿Cuál es el sentido actual de los apuntes y reflexiones que se inscriben bajo el título "Pedagogía"? Suele distinguírsela de la didáctica atribuyéndole a esta última un lugar más práctico, más ligado a la enseñanza y sus quehaceres, y reservando para la pedagogía el espacio de la reflexión más amplia, sensible y abierta sobre la educación. Si en la formación se enseñaran acaso disciplinas más teóricas y más prácticas, a la pedagogía suele situársela del lado de las teóricas. Sin embargo, en la asignatura "Pedagogía" de los institutos formadores no es inusual que, desde el primer día, se instruya a los maestros sobre los sentidos que demanda la reforma de la escuela, antes incluso de terminar de preguntarse qué es una escuela, cómo funciona o qué efectos esparce en su institucionalidad. Pareciera que la teoría pedagógica, basada en un consenso más o menos indiscutido acerca del fracaso de la escuela como institución social, tiene una tarea más performativa y menos descriptiva, más orientada a las prácticas, y menos a la reflexión. A este imperativo reformista se suma que la tesitura de la reflexión pedagógica se halla rodeada, casi sitiada, por demandas de aplicacionismo, eficientismo, ajuste a las demandas operativas del mercado laboral, absorción de imperativos tecnológicos, neurocientíficos, legislaciones del afecto, y algunos otros etcéteras, frente a los que la pedagogía merece ser vista (nuevamente) como el lugar desde el que es posible pensar, volver a pensar, seguir pensando, los sentidos de la educación y de la escuela.

La teoría, sin embargo, sobrevive a las embestidas, y la pedagogía, que es un lugar desde el que se piensa la educación (y especialmente la que tiene lugar en las escuelas) sigue constituyéndose en un espacio privilegiado para ejercer ese acto de pensamiento. ¿Y de qué está hecho este lugar? De lenguaje, claro. $Y$ de una búsqueda permanente e inconclusa de lenguas que puedan pensar lo educativo. $Y$ de la disputa entre distintas lenguas. Como dice Carlos Skliar, "toda política de la lengua se sitúa justamente en ese plano de la expropiación de la experiencia del otro, en ese ordenamiento de lo que es inapropiable y en esa soberbia de querer desvelar aquello que tiene de misterioso, de indefinible, de innombrable" (2005, p.2). La pedagogía se constituye como escenario de estas disputas, y a las producciones que van dejando las investigaciones, los ensayos, los debates, las llamamos usualmente teoría pedagógica. Esas escrituras no son, sin embargo, la expresión acabada de un saber unívoco, sino que son el escenario en el que estos saberes se construyen, se reúnen y se desencuentran. No sólo porque respondan a distintas cosmovisiones o intereses, sino también porque conversar, pensar y escribir son los puntos de partida y de llegada de la pedagogía, y las conversaciones, pensamientos y escrituras tienen, por lo general, una tesitura abierta y porosa.

En este marco, la intención de estas páginas es apenas la de sostener algunos apuntes sobre las geografías de ideas, reflexiones y preguntas que pueden pensarse desde la pedagogía en la frágil coyuntura de este presente que nos toca habitar: recorrer el abanico de sentidos que la idea de "teoría" 
contiene en el discurso pedagógico actual. Porque decir "teoría" puede significar una gran cantidad de cosas diferentes. En las siguientes páginas, ensayaré un intento de desmenuzar algunas de las certezas que reposan detrás de la palabra "teoría" en el universo pedagógico. Para ello, se revisarán siete hipótesis, que dan vida a siete sentidos diferentes del quehacer teórico en educación.

\section{LA TEORÍA COMO REGLAMENTO: UNA GUÍA PARA LA ACCIÓN}

Teoría y práctica se reúnen a veces en una suerte de cita a ciegas, en la que cada parte ha sido apalabrada para enlazarse a la otra. La teoría es, desde esta perspectiva, una especie de reverso leguleyo de la realidad, a la que se debe recurrir para constatar una necesaria coincidencia. Un estudiante del magisterio, impulsado por esta concepción de la teoría, observará entonces una situación de clase, agazapado en un rincón del aula, esperando reconocer en la actividad de los alumnos la teoría que estudió. Celebrará el feliz avistaje de una zona de desarrollo próximo vigotskiana, de una asimilación, una acomodación o un esquema piagetianos, de un andamiaje, y los irá tachando de su lista. La teoría, en este caso, es una norma que la realidad cumple, obediente. La enseñanza, por su parte, se basa en la teoría como en un método: ordena las acciones concretas.

En esta concepción de la teoría, lo teórico se parece a una guía o instructivo que, a modo de reglamento, dictamina los pasos a seguir dentro de un campo determinado: el aula, la escuela, la gestión, etc. Si hemos decidido que una enseñanza está basada en el enfoque de proyectos, por ejemplo, esto supondrá asumir el ajuste a una serie de regulaciones explícitamente trazadas por las teorías de los proyectos áulicos. Si así no fuera, quien asumiera el rol de supervisar (el director escolar, el profesor de prácticas, el analista furtivo) observarán: a este proyecto le faltan los tres pasos de todo proyecto: el 1 , el 2 y el 3.

Suele decirse que los reglamentos resultan útiles allí donde no existen acuerdos posibles, y las relaciones fallan. "A mis amigos, todo", dice el refrán, "y a mis enemigos, la ley". Es cierto, por supuesto, que los reglamentos garantizan muchas veces el cumplimiento de los derechos, pero a la vez rigidizan la interacción entre las personas. Es por ello que la concepción de la teoría como un reglamento rígido comporta ciertos peligros. El principal de ellos es que las personas pierdan la posibilidad de pensar desde la teoría por someterse con demasiado respeto a sus arbitrios, y dejen que la teoría piense todo por ellos. Como señalaba Eisner en un texto de los años 80', analizando el uso rígido de los objetivos educacionales: estas previsiones pueden complicar tanto como ayudar a los fines de la enseñanza, en la medida en que una creencia no analizada puede fácilmente dogmatizarse.

\section{LA TEORÍA COMO ESCRITURA SAGRADA: UN CANON ELEVADO}

La referencia a los libros científicos como alegoría de los textos sagrados no es nueva. Las ideas de Galileo desafiando las teorías aristotélicas fueron consideradas heréticas porque las verdades que desafiaba revestían cierto carácter religioso. Pero sin ir tan lejos, pueden reconocerse un tono sacro en los usos bibliográficos cuando algunos autores son citados casi como si se tratara de referencias bíblicas. La lectura rigurosa (en el sentido de literal) y doctrinaria de los autores llamados 
clásicos ha devenido en la definición del autor como un semidiós iluminado cuyas palabras publicadas instalan verdades indiscutibles. Bourdieu dixit: es palabra de Bourdieu. Te adoramos, Bourdieu. Como en un conocido soneto de Quevedo, el acto de leer se entiende como una conversación con los muertos $^{2}$. Y a los muertos, ante todo, se los respeta.

Esta hermenéutica bibliográfica que instala la idea de que los textos publicados y devenidos "bibliografía" elevan su contenido a un status sacro se reconoce también en los rituales de la cita. $\mathrm{Al}$ respaldar afirmaciones en un texto pedagógico, la referencia bibliográfica aparece como evidencia, de un modo similar al que, en sus afirmaciones genéricas, el pastor trae a colación lecturas de los profetas o los apóstoles. En forma análoga, existen modos de asumir la teoría en las que los conceptos y metáforas que las conforman se vuelven referencias con un valor de verdad otorgado por el proceso editorial y por el status de los autores dentro de las comunidades académicas.

Como en todo proceso de sacralización, por supuesto, aparecen los fieles a cada doctrina, y los irrenunciables embanderamientos. Foucaultianos, derridianos, gramscianos, piagetianos, lacanianos, freireanos, comenianos, conviven con constructivistas, eficientistas, escolanovistas, tecnicistas... Como banderas de pertenencia, las teorías sacralizadas clasifican el pensamiento y a los que piensan. Los foucaultianos, entonces, verán panópticos a la vuelta de cada esquina, los gramscianos hegemonías, los conductistas respuestas condicionadas, y así sucesivamente. Quizás a eso se refiere Carlos Skliar cuando describe su "conversación sin disfraces" con una profesora de filosofía, donde reconoce el deseo de "(...) esquivar la pregunta acerca de "lo que pasa en la educación" (en tanto interrogante que apunta y se dirige a una exterioridad) y atravesar juntos la pregunta acerca de "lo que nos pasa en la educación", sin zancadillas, sin trucos de magia, sin armas de guerra, sin estridencias, sin fuegos de artificio" (Skliar, 2010:138, el destacado me pertenece). Y es que la teoría sacralizada, en efecto, genera sectas poderosas con adeptos fanáticos que empuñan los conceptos como rifles y los apuntan contra los paganos.

\section{LA TEORÍA COMO HERRAMIENTA: UNA BATERÍA DE RECURSOS}

Una visión más pragmática de la teoría tiene que ver con su concepción como un conjunto de herramientas que pueden aplicarse a la solución concreta de ciertos problemas. La teoría como un insumo, como un recurso del que echar mano cuando es preciso ordenar acciones, pensamientos, justificaciones, fundamentos, decisiones. Foucault resaltaba una visión de la teoría como "caja de herramientas" partiendo de la idea de que "no se trata de construir un sistema sino un instrumento, una lógica propia a las relaciones de poder y a las luchas que se comprometen alrededor de ellas (...) y esta búsqueda no puede hacerse más que poco a poco, a partir de una reflexión (necesariamente histórica en algunas de sus dimensiones) sobre situaciones dadas" (Foucault, 1985:85). La idea de

\footnotetext{
${ }^{2}$ Retirado en la paz de estos desiertos,/ con pocos, pero doctos libros juntos,/ vivo en conversación con los difuntos/y escucho con mis ojos a los muertos.//Si no siempre entendidos, siempre abiertos,/ o enmiendan, o fecundan mis asuntos;/ y en músicos callados contrapuntos/ al sueño de la vida hablan despiertos.// Las grandes almas que la muerte ausenta,/ de injurias de los años, vengadora,/ libra, ioh gran don Josef!, docta la emprenta.// En fuga irrevocable huye la hora;/ pero aquélla el mejor cálculo cuenta/ que en la lección y estudios nos mejora.
} 
herramienta aparece allí como lo contrario del sistema totalizador. Se trata de tomar la teoría como una herramienta (de pensamiento) pero sin someterse a ella, sin comprar todo el paquete. Sin sacralizarla ni considerarla un reglamento. La teoría "no es entonces un sistema totalizador que suministraría un sentido y una representación del mundo (...) [sino] un conjunto de instrumentos para investigar la realidad. En lugar de dogmas sobre su naturaleza, medios para operar esa realidad" (Martínez Boom, 1990). A la vez, esta visión de la teoría instrumental como un intento de huir de la fuerza totalizadora de las grandes teorías convive con una visión más aplicacionista, donde la idea de herramienta se destaca por su maleabilidad, por su uso más o menos práctico e inmediato, por su fácil disponibilidad. De este modo, instrumentalizar la teoría puede ser una búsqueda del pensamiento propio, al rehuir de los sistemas teóricos demasiado determinados, esos que no ayudan a pensar, sino que piensan por uno. Pero a la vez, puede ser un intento por mecanizar las ideas, subrayando sólo su utilidad, y en ese caso, es un procedimiento que se opone al pensamiento. Estas dos visiones que subyacen a la idea de la teoría como una herramienta, entonces, son más o menos opuestas, pues remiten a concepciones dicotómicas acerca del sujeto y su relación con las ideas.

Para los docentes, es muy habitual concebir las lecturas pedagógicas y, las experiencias de formación, como espacios para adquirir herramientas, entendidas muchas veces literalmente como herramientas metodológicas. Y tiene sentido: el oficio del maestro es demandante de intervención, y se trata de una demanda fuerte y constante ante la que esta concepción de la teoría se presenta como promesa de eficacia ante la que es difícil no dejarse seducir.

\section{LA TEORÍA COMO FUNDAMENTACIÓN O CÓDIGO DE ÉTICA: UN RESPALDO}

Intentemos partir de una escena escolar. La maestra se dispone a servir el desayuno a sus alumnos de tres años, en la sala del jardín de infantes. Dispone el espacio, los chicos se sientan, y un "ayudante" (un niño que ha sido designado por la maestra) reparte los vasos. Cuando los chicos los reciben, algunos comienzan a golpearlos contra la mesa. El golpeteo seduce al resto, y enseguida todos están golpeando la mesa con los vasos, rítmicamente. La maestra les dice: - "No golpeemos el vaso, chicos, que voy a servir el desayuno". Siguen. - "Basta, por favor...". Siguen. "Más tarde tocaremos instrumentos musicales, pero ahora estamos merendando y necesitamos hacer silencio...".

Pero los chicos siguen golpeando, muy divertidos y sin prestar la menor atención a lo que la maestra les dice. En ese momento, entonces, la maestra golpea con fuerza la mesa. Se produce un silencio absoluto. - "No se pueden usar los vasos para golpear. ¡No son para eso!", dice finalmente. $Y$ sirve la leche.

Si esta escena fuera presentada a educadores de la primera infancia para ser analizada, probablemente la cuestión se plantee en términos de un dilema ético: ¿está bien o está mal lo que hizo la maestra? ¿actuó correctamente? Y, naturalmente, la respuesta a esa pregunta es, como casi siempre, bivalente. Lo que hizo la maestra está bien o está mal, dependiendo de cómo se fundamente.

Está bien, por ejemplo, si se piensa que toda libertad se basa en la imposición de un límite. EI "no", el "basta", es una experiencia que funda el propio psiquismo. De un modo u otro, siempre hay un límite, y ese límite siempre será vivido con cierto desagrado por quien resulta limitado. Desde este 
punto de vista, no les haríamos ningún favor a los niños "edulcorando" siempre los límites con canciones o juegos. Hace falta interiorizar la Ley (que nos protege, que nos convierte en personas sociales) y eso sólo se logra sometiéndose a ella, percibiéndola como justa y necesaria. Aunque tenga una apariencia violenta, la intervención de la maestra no hace otra cosa que garantizar el derecho a esa Ley justa que cuida a los niños. Y para hacerlo, ante la fragilidad de la palabra, su golpe en la mesa puede verse como un acto de dulce firmeza dirigido a custodiar un orden necesario.

Pero a la vez, podríamos decir que está mal, porque la acción de la maestra (golpear la mesa) es idéntica a la acción que pretende sancionar (golpear la mesa), y al hacerlo como medio para imponer el límite, deja ver un mensaje contradictorio y autoritario: lo que prima es la fuerza del fuerte, la primacía de quien detenta el poder. Pero como el docente no debería ser un dictador poderoso, sino un juez bondadoso y siempre dispuesto a escuchar y contemplar opciones, esa intervención sería, desde esta perspectiva, incorrecta.

Lo que fundamenta cada argumento es teoría, es concepto, es pensamiento puesto al servicio de respaldar la acción desde la perspectiva ética. Y muchas veces la teoría es empleada como esta suerte de deontología, de código de ética profesional. Incluso los nombres de las grandes teorías, las más ideologizadas, remiten muchas veces a un sustrato de esta naturaleza. "Lo que hace ese profesor es demasiado conductista", se dirá, o bien: "muchos profesores son constructivistas para enseñar y conductistas para evaluar".

Teorizar con palabras, esto es, adjudicar a un término específico la densidad de unas connotaciones, unos sentidos, unas formas de relacionarse con la época, con otros términos, con las tradiciones, forma parte de esta constitución de la teoría en sustento ético. No sólo y no tanto porque las teorías aborden cuestiones como el bien, el mal o la verdad, sino porque al investir a una palabra con esas resonancias, se diferencia el sentido en el que se dicen las cosas, y se sugieren consecuencias y derivaciones. No es lo mismo decir "poder" desde una lectura posestructuralista que decirlo desde una teoría de la organización. No da igual decir "cultura" desde los estudios de la gramática escolar o la etnografía educativa, que desde las teorías del liderazgo. Cuando la psicología dice "niño", no dice lo mismo que la pedagogía. Y cuando la didáctica habla de "aprendizaje", definitivamente no se refiere a lo mismo, ni en los mismos términos ni por las mismas razones, que los estudios críticos de la learnificación de la escuela.

\section{LA TEORÍA COMO VOCABULARIO: UN GLOSARIO PARA MIRAR}

Ya lo hemos dicho: los nombres que se da a las cosas se inscriben en las batallas eternas y siempre cambiantes entre distintas cosmovisiones acerca del mundo. En el caso de la teoría educativa, como en otros campos, estas cosmovisiones se dirimen entre distintos criterios y supuestos empleados para justificar los modos de construir, distribuir o legitimar lo que se hace en las escuelas. Por eso, porque se trata de una batalla constante entre puntos de vista, intereses e ideologías, en el mundo educativo un mismo hecho empírico, una misma cosa, puede verse muy diferente según desde qué jergas se la nombre. Conceptualizar a la escuela como terreno de ejercicio de cierta violencia simbólica, por ejemplo, sugiere unas disposiciones muy diferentes de las que surgen de definirla como 
ámbito de socialización secundaria. Decir de una experiencia atípica que es innovadora subraya algo diferente de lo que supondría llamarla disruptiva. Muchas prácticas a las que algunos destacan por ser eficaces son denostadas por otros como ejemplos de una racionalidad utilitarista o neoliberal. Para algunos la educación es concientizadora si ahonda en ciertos territorios políticos, para otros es adoctrinante, según el sentido - crítico o subyugante - que se asigne a la ideología. Y la lista podría seguir en forma extensa.

Teorizar es nombrar. Nombrar públicamente y a conciencia, y asumir así un lugar simbólico dentro de un sistema amplio de opciones disponibles, ya que todo bautismo supone la asunción de algún tipo de herencia. Cuando hablamos de educación no sólo nos damos a entender por el contenido del mensaje, sino también (y quizás fundamentalmente) por el vocabulario que elegimos. Convertirse en educador no es sólo aprender algunas técnicas, algunos problemas, sino también hacer propia una lengua. $\mathrm{Y}$ en este punto, sucede que no hay una lengua única para hablar de la educación, y la búsqueda de una lengua es una quimera constante detrás de la que caminamos contantemente.

En este punto, es interesante distinguir entre dos tesituras del lenguaje educativo que contrastan con bastante nitidez: una lengua a la que podríamos llamar técnica, y otra lengua éticacrítica, o simplemente reflexiva.

Si nos detuviésemos a escuchar conversaciones entre educadores acerca de su tarea y su oficio, si detectásemos cuáles son los términos que pertenecen a la jerga propia del oficio y fuéramos detectando sus usos específicos, listándolos, poniendo juntos los que van juntos, podríamos reconocer que conviven allí al menos dos grupos de palabras. Unas más técnicas, que pertenecen a una conversación acerca de cómo llevar a cabo la enseñanza (planificando, siguiendo tal o cual método, formulando objetivos, etc.) y otras más filosóficas o reflexivas, que pertenecen a una conversación acerca de cómo volver sobre lo que hacemos habitualmente para pensarlo mejor, para revisar sus efectos, para cuestionarnos las certezas en las que ese quehacer consolidado, reposa.

Entre las típicas palabras "técnicas", podríamos señalar términos como: contenido, evaluación, metodología, organización, gestión, planificación, unidad didáctica, secuencia, objetivos; mientras que entre las palabras reflexivas entrarían términos como: igualdad, discriminación, diversidad, inclusión, pensamiento crítico, compromiso, poder.

Unas palabras como piezas de una ingeniería del hacer, frente a otras palabras como alientos de una revisión crítica de ese mismo hacer. Palabras prácticas y palabras reflexivas. Palabras útiles al necesario buen funcionamiento de un sistema, y palabras rebeldes que lo interrogan y lo cuestionan. Palabras técnicas y palabras filosóficas. A las palabras del hacer, les pedimos que sean eficaces para acompañarnos en la tarea, que nos faciliten las cosas, que nos permitan resolver tareas y problemas cotidianos. De las otras, esperamos que nos mantengan atentos, que nos adviertan sobre las paradojas, los falsos semblantes. Que nos ayuden a leer entre líneas.

Esta distinción abre dos discursos diferentes - muchas veces enfrentados - que protagonizan un forcejeo por consolidar las bases del sentido común pedagógico. Jorge Larrosa señala cómo el "lenguaje de la técnica" y el "lenguaje de la crítica" ponen a tecnólogos y críticos en un lugar de soberanía para decirnos con qué palabras debemos hablar de la educación: de la educación que hay (la técnica) y de la que se supone que debe haber (la crítica) (Bárcena, Larrosa y Mèlich, 2006, p.246). 
En el medio, dice Larrosa, falta una lengua en la que podamos conversar honestamente, preguntarnos, interpelarnos.

Cuando se piensa desde las preocupaciones metodológicas, el lugar del docente se vive como un laboratorio desde el que se experimentan acciones y reacciones, estilos, formatos, tesituras posibles para el tiempo intenso y meditado que pasamos con los alumnos. El maestro es arquitecto de esa escena, y la piensa al detalle: cómo ubicarse en el espacio, qué hacer al comienzo, cómo conmover, cómo hacer pensar, cómo invitar a leer y a estudiar, cómo darse cuenta si entendieron, si aprendieron. Para el enseñante, las palabras técnicas son herramientas que van cayendo en sus manos, y pronto se hallará empleándolas, admitiéndolas en el discurso, eligiendo unas antes que otras, y dándoles el uso práctico y funcional que se supone deben tener. Cuando se piensa desde las preocupaciones éticas y críticas, en cambio, el lugar del docente se convierte en un atelier filosófico, en un salón de espejos en el que volver a mirarse, una y otra vez, para atisbar el sentido profundo de la enseñanza, de la formación.

Pronunciar los términos usuales, extrañarse de la comodidad con la que se instalan en nuestra voz, balbucear palabras nuevas, todo ello forma parte de aquello a lo que llamamos teoría pedagógica.

\section{LA TEORÍA COMO PENSAMIENTO: REVISIÓN CONSTANTE DEL SENTIDO}

La teoría entendida desde las concepciones anteriores (como reglamento, como escritura sagrada, como herramienta, como fundamentación y como vocabulario) se abre en un abanico de sentidos diferentes, pero todas las imágenes tienen en común cierta concepción de verdad subyacente a la teoría. Hay un elemento afirmativo que bien deriva en reglas, bien en cánones, en recursos, en jergas, pero que no deja de formularse en forma más o menos asertiva. Concebir a la teoría como pensamiento es una invitación a abandonar ese tono imperativo e incursionar en una teoría que pregunta, que duda, que sospecha. Hacer teoría desde este lugar de puro pensamiento (¿de "teoría pura"?) no utilitario, ni moral, ni puesto al servicio de prácticas de ningún tipo, es un acto de soberanía del pensamiento y si acaso sirve para algo, podemos decir que nos ayuda a desnaturalizar la realidad cotidiana, a mantenernos atentos.

En este punto, la teoría es una gimnasia o entrenamiento intelectual que, si debe parecerse a algo, se parece bastante a los ejercicios escolares como los conciben Simons y Masschelein, como oportunidades para el estudio y la práctica desvinculados de toda finalidad externa. La escuela, dicen "es un lugar que convierte algo en objeto de estudio (en conocimiento por amor al conocimiento) y en objeto de práctica (en habilidad por amor a la habilidad)" (2014, p.66). La teoría entendida como pensamiento es un acto de estudio, también en sentido escolar, porque ese "pensar por pensar" enfatiza la idea de que pensar vale la pena, y que no debe pensarse sólo a la hora de resolver problemas. Pensar nos eleva por sobre nosotros mismos, y nos dice algo acerca de lo que somos, y de lo que somos capaces.

La idea de estudio tiene una etimología interesante, que destaca Larrosa (2019a). Proviene del vocablo latino studium, que significa: empeño, aplicación, celo, ansia, cuidado, desvelo, y también afecto. La expresión studia habere alicuius, por ejemplo, quería decir "gozar del afecto de alguien", y 
studio legendi podría traducirse como 'dedicación a la lectura'. Por eso, dice Larrosa, el estudio es "una actividad libre y no definida por su utilidad"; los que estudian, lo hacen "para que puedan aplicarse con atención, disciplina, perseverancia y celo a ejercitarse en cosas que no están en la casa, ni en la televisión, ni en la plaza ni en el shopping: a cosas que valen la pena por sí mismas" (Ibíd, p.134).

La teoría como pensamiento se analoga así a un acto de estudio en este sentido de pensamiento guiado por el amor al mundo, por el empeño en entenderlo, y nos remite a las figuras arquetípicas de amantes del pensamiento, a los filósofos clásicos, a los científicos, a los poetas.

\section{LA TEORÍA COMO CONVERSACIÓN}

La última de la hipótesis que quisiera proponer es la de la teoría pedagógica como una conversación, que merece un lugar destacado pues se inspira precisamente en el tipo de conocimiento que se construye en las aulas. Implica, entonces, hablar de educación en el lenguaje que más habitualmente la educación escolar se materializa, que es la del encuentro entre profesores y estudiantes. En un libro reciente he definido al encuentro del aula en términos conversacionales (Brailovsky, 2019). Lo que hace el aula, decía allí, es que un grupo de personas desconocidas entre sí se vuelven íntimas por un rato, y entablan una conversación profunda, abierta, guiada por el deseo de conversar (y no, por ejemplo, de persuadir, o de tener razón) sobre ciertos asuntos que se ponen allí, en el centro del aula, para ser objetos de esa conversación. El aula es uno de los poquísimos lugares (sino acaso el único) en el que sucede tal cosa. La conversación que tiene lugar en una clase se distingue porque es un encuentro entre desconocidos que no buscan conocerse, ni celebrar su amistad en la charla, ni meramente pasar un buen rato: los convoca el propio fin de conversar, a sabiendas de que esa conversación los modifica, los afecta. Lo dice bellamente Carlos Skliar, dialogando con un texto de Nuria Pérez de Lara: se trata de seguir donando a desconocidos, entre desconocidos, dando la bienvenida al desconocido, celebrando el recibimiento dado de un desconocido a otro desconocido (2012, p.182).

Por ser un encuentro íntimo y público a la vez, atravesado de ritualidades y modos de estar que potencian esa posibilidad de conversar, y donde lo que se celebra es el conocimiento, el saber, el ancho mundo alrededor, es tal vez la forma máxima de esta concepción final de la teoría como conversación.

Cuando la teoría es un acto de conocimiento, cuando es acción compartida, es conversación. Y ese punto, siempre está oscilando entre contrastes: se conversa nombrando un mundo a la vez oculto y a la vista (porque hay que interrogarlo para que se muestre), está a la vez en calma y en peligro (porque la conversación revela del mundo sus lógicas implacables, tanto como sus contradicciones, sus abismos insospechados). Y desde el aula, el mundo se vuelve un lugar posible de ser habitado desde distintas posiciones y sensibilidades, porque es precisamente la conversación la que nos abre a esos mundos y esas sensibilidades.

Y la teoría conversacional es, además, un encuadre para el pensamiento que tal vez precede a (y es condición de) cualquier otro "uso" de la teoría. Pero para conversar se renuncia a esa utilidad, a ese uso, y se discurre gozosamente. $Y$ cabe observar, para finalizar, que la conversación demanda aún 
otras renuncias. En primer lugar, por supuesto, la renuncia a cualquier forma de certeza absoluta, a la verdad cerrada, al punto de llegada predefinido. Si la conversación es abierta, sus devenires son necesariamente difusos. Una segunda renuncia necesaria es la de la corrección política. La posición política o ideológicamente correcta, aunque bienintencionada, siempre tiene algo de impostura y atenta contra la honestidad, la autenticidad del encuentro. En la conversación (como en la literatura) es preciso poder hablar sin miedo a que las palabras rompan algo, si temor a lastimarse. En todo caso el léxico será objeto de conversación también, ya que no pocas veces las conversaciones son metaconversaciones, y se asoman hacia sí mismas de un modo abismal. Pero al conversar construimos un relato que no es ni ideológico, ni didáctico, ni deviene en moralejas ortopédicas. De la conversación puede decirse lo que dice Alba Rico acerca de los relatos: son "botiquines de supervivencia que incluyen las piezas necesarias para levantar un mundo, y sostenerlo, en medio de la lava sin fronteras" $(2015$, p.62).

Finalmente, conversar implica renunciar a la complacencia, a la creación de espacios cómodos y sin preguntas, cedidos al otro por compasión, por pereza o por cobardía. Porque la escena conversacional no es un duelo de argumentos en el que puede dársele ventajas de cortesía al adversario, sino una construcción conjunta, un recorrido a pie, un viaje compartido.

\section{REFERÊNCIAS}

1. ALBA RICO, S. (2015). Leer con niños. España: Literatura Random House.

2. BÁRCENA ORBE, F., LARROSA BONDÍA, J. y MĖLICH SANGRÁ, J. (2006) Pensar la educación desde la experiencia, revista portuguesa de pedagogia, ano 40-1, 2006, 233-259.

3. BOOM, A. M. (1990). Teoría Pedagógica. Una mirada arqueológica a la pedagogía. Pedagogía y Saberes, (1), 7-13.

4. BRAILOVSKY, D. (2019) Pedagogía (entre paréntesis), Buenos Aires: Noveduc.

5. EISNER E. (1985) Los objetivos educativos: ¿Ayuda o estorbo?, en J. Gimeno Sacristán y A. Pérez Gómez: La enseñanza, su teoría y su práctica, Madrid: Akal.

6. FOUCAULT, M. (1985). Poderes y Estrategias, En: Un diálogo sobre el poder y otras conversaciones. Alianza Ed., Madrid.

7. LARROSA, J. (2019a) Vindicación del estudio como concepto educativo: a propósito de aprender / estudiar una lengua, Teri. 31, 2, jul-dic (pp. 131-151). 
8. LARROSA, J. (2019b). Esperando no se sabe qué: sobre el oficio del profesor, Buenos Aires, Noveduc.

9. SKLIAR, C. (2012). Acerca de la alteridad, la normalidad, la anormalidad, la diferencia, la diversidad, la discapacidad y la pronunciación de lo educativo. Gestos mínimos para una pedagogía de las diferencias, en: Almeida, M. E., \& Angelino, M. A. (coord.) (2012). Debates y perspectivas en torno a la discapacidad en América Latina. Paraná: Universidad Nacional de Entre Ríos. UNER. Facultad de Trabajo Social. - http://sedici.unlp.edu.ar/handle/10915/26338.

10. SIMONS, M. y MASSCHELEIN, J. (2014). Defensa de la escuela. Una cuestión pública. Buenos Aires: Miño y Dávila.

11. SKLIAR, C. (2005). Notas para una confusión pedagógica, Documento de UNTER, disponible en http://unter.org.ar/imagenes/11571.pdf (descargado en octubre 2019).

12. SKLIAR, C. (2010). La experiencia de la conversación, de la mirada y de la investigación educativa. Una desnaturalización de la incongruencia, en Contreras Domingo, J. y Perez de Lara, N.: Investigar la experiencia educativa, Madrid: Morata.

\section{Daniel Brailovsky}

Daniel Brailovsky es Doctor en Educacion. Docente e investigador en Flacso/Argentina y formador en ISPEI Eccleston. Su libro más reciente es Pedagogía (entre paréntesis), Buenos Aires: Novedades Educativas, 2019.

\section{Como citar este documento:}

BRAILOVSKY, Daniel. Siete vidas de la teoría pedagógica. Reflexão e Ação, Santa Cruz do Sul, v. 28, n. 2, jun. $2020 . \quad$ ISSN 1982-9949. Disponível em: <https://online.unisc.br/seer/index.php/reflex/article/view/14443>. Acesso em: doi:https://doi.org/10.17058/rea.v28i2.14443. 